\title{
National Lottery_-You Can Win As Well: A Metaphor Study on Disabled Athletes
}

\author{
Atike Yilmaz ${ }^{1} \&$ Gozde Yetim $^{1}$ \\ ${ }^{1}$ School of Physical Education and Sport, Mus Alparslan University, Mus, Turkey \\ Correspondence: Atike Yilmaz, School of Physical Education and Sport, Mus Alparslan University, Mus, 49250, \\ Turkey. Tel: 90-436-249-2125. E-mail: a.yilmaz@alparslan.edu.tr
}

Received: December 18, 2019

doi:10.5539/ies.v13n4p54

\author{
Accepted: January 19, $2020 \quad$ Online Published: March 9, 2020 \\ URL: https://doi.org/10.5539/ies.v13n4p54
}

\begin{abstract}
The aim of this study is to determine the metaphoric perceptions of physically disabled and hearing impaired athletes concerning their branches and concepts about these branches. In this context, the sample of the study was comprised of 20 physically disabled and hearing impaired athletes playing in the basketball and football teams in Muş province. In the form that was prepared for data collection, the participants were asked to answer certain statements such as "Basketball/football is like ... Because, ...", "Field/court is like ... Because, ...", "Basketball/football (the ball) is like ... Because, ...", "Playing basketball/football is like ... Because, ...", etc. The obtained data were transferred to the SPSS program, and frequency and percentage analyses were conducted. As the conclusion, it was determined that the sports branches of physically disabled and hearing impaired athletes were the focal points of their lives, and they perceived them as the requirements for their lives. In this respect, it is considered that the results of this study are significant since it suggests encouraging disabled individuals to sports, helping them participate in sports, providing support, and promoting the disabled sports.
\end{abstract}

Keywords: sport, metaphor, physically disabled athletes, hearing impaired athletes

\section{Introduction}

Although involves a dynamic structure, disability is a concept that includes special differences within itself. Disability was defined by the World Health Organization as a dynamic interaction between the health conditions and environmental factors. This classification is supported as a bio-psycho-social model, and it represents a consensus among the medical and social models. In this regard, disability is defined as an umbrella term for impairments, activity limitations, and participation restrictions (WHO, 2017). In this context, it is understood that the term disability was not defined on a single fact, it was rather based on the whole life of an individual with a sense of integrity. Providing the integration of the disabled individuals in the society, full participation, independent life, and economic self-sufficiency are among the responsibilities of all societies. It was stated in the Convention on the Rights of Persons with Disabilities as follows: "The objective of the convention in the $1^{\text {st }}$ article was stated as 'to encourage, protect and ensure the full and equal enjoyment of all human rights and fundamental freedoms by all persons with disabilities, and to promote respect for their inherent dignity."”

In this respect, one of the rights and freedoms of individuals with disabilities is to equally enjoy the right to play sports. Especially it is a necessity to start sports trainings from early childhood. A sport is primarily a physical activity and then a game, a means of interaction, and socialization among individuals (Kaya, 2018; Siedentop, 1998; Kemper et al., 2000). The ability of sports to bring societies and individuals together has a significant impact on the socialization of individuals. This effect has also been noted in studies, especially the ones conducted on individuals with disabilities (Sherrill, 1998; Jaarsma et al., 2015; Kissow, 2015; Nemček, 2016; Winnick \& Porretta, 2016; Lastuka \& Cottingham, 2016; Lorenzo, 2019). Considering that $15 \%$ of the world's population is consisted of disabled individuals, the importance of sports is once again understood in the integration of these individuals into the society as well as in their physical, mental, and psychological developments. In line with their interests, abilities, and needs, it is a social responsibility to encourage people with disabilities for sports at an early age, to ensure their participation in sports, and to promote disabled sports.

Today, disabled individuals deal with various sports branches in parallel to the types and degrees of their disability. One of these types of disabilities is the hearing impairment. Having differences in hearing varying from very mild to very advanced degree is called as a hearing insufficiency. In other words, hearing is a state of inability to 
perform one's duties in development, harmony, and especially in communication. It affects not only the language and speech development, but also mental, social, and emotional development of an individual (Bilir, 1986; S. Aslan, U. Aslan, \& Uyan, 2017). Certain differences may occur in the individuals with hearing impairment based on the type and degree of the hearing loss, the age of the loss, the level of intelligence, the socio-economic status, attitudes, and possibilities of the family and the society in which the individual lives, the level of coping with hearing impairment, etc. In this regard, sports is an effective means in coping with these differences. Stewart \& Ellis (2005) defined the most important feature of sports for the hearing impaired individuals as meeting the need of the hearing impaired athletes to be included in a group regardless of their age, gender, educational status, interest and levels in sports. It was reported that sports facilitates group processes and the formation of social identity through interaction and communication among groups (Stewart \& Ellis, 2005; Stewart, 1991). The effects of sports on hearing impaired individuals were also mentioned in other studies (Shahan et al., 2016; Aslan, 2019). Another type of disability is the physical disability. Physical disability is defined as having difficulties in adapting to social life and meeting the requirements of daily life as a result of disorders in the skeletal, muscular, and nervous system with any cause before, during, and after birth (Butler \& Darrah, 2001; Özyürek, 2012; Mayston, 2005). In studies conducted on physically disabled individuals, it was stated that sports contributes to the development and integration of individuals with physical disabilities (Brittain, 2004; Goodwin et al., 2004; Taub \& Greer, 2000; Devas, 2003).

In addition to these benefits of sports, it is important to understand how sports are perceived and understood by individuals with disabilities. Metaphors are often used to examine people's expectations, beliefs, attitudes, and perceptions. Morgan (1980) described metaphors as "a way of seeing and understanding the world, rather than being a word art." Lakoff \& Johnson (2015) emphasize the importance of metaphor because it deeply affects an individual's attitudes, perceptions, and worldview, and state that metaphors are not only a form of speech and perception, but also a way of thinking. In this respect, our study was carried out to examine how hearing impaired and physically disabled athletes perceive and understand their branches. In line with this purpose, it is thought that the results of the study are important since they will provide an insight and raise awareness for the existing and future researchers of this field and policymakers.

\section{Method}

\subsection{Research Model}

In this study, the phenomenology design was used, which is one of the qualitative research designs. Phenomenology is defined as focusing on phenomena that we are aware of but we do not have a detailed and in-depth insight (Yıldırım \& Şimşek, 2011).

\subsection{Data Collection}

In the collection of the research data, physically disabled and hearing impaired athletes were asked to create metaphors concerning their branches and concepts in their branches, with justification. In this respect, the participants were asked to answer certain statements such as "Basketball/football is like .... . Because, ...", "Field/court is like ... Because, ...", "Basketball/football (the ball) is like ... Because, ...", "Playing basketball/football is like ... Because, ....", etc. In the last part of the form, there is information concerning their demographical properties.

During the data collection phase, the athletes with physical disabilities were informed about the study, subsequently, they filled out the forms themselves. As per the hearing impaired athletes, the forms were filled out through a sign language specialist. Subsequently, the created metaphors were read and approved by the hearing impaired athletes. Athletes were not guided in any way during the data collection phase in both groups.

\subsection{Data Analysis}

In the analysis of data obtained from athletes with physical disabilities; 9 metaphors emerged for basketball, 6 for basketball court, 6 for basketball (ball), 9 for playing basketball, 4 for basketball teammates, 6 for basketball coach, 7 for basketball supporters, 8 for having physical disability, 8 for having hearing impairment, and 10 for being disabled.

In the analysis of data obtained from hearing impaired athletes; 8 metaphors emerged concerning football, 9 for football field, 8 for football (ball), 7 for playing football, 10 for football teammates, 9 for football coach, 9 for football supporters, 10 for having physical disability, 6 for having hearing impairment and 9 metaphors for being disabled. The resulting metaphors were transferred into the SPSS 23 program, and frequency and percentage analyses were performed. 


\subsection{Participants of the Study}

The research group is comprised of 10 physically disabled and 10 hearing impaired athletes who are playing in the male basketball and football teams in Mus province. The age, basketball/football playing experience and educational status of the physically disabled and hearing impaired athletes are presented in Table 1 and Table 2 .

Table 1. Demographic characteristics of physically disabled participants

\begin{tabular}{cccccc}
\hline Age & $\mathrm{f}$ & $\%$ & How long playing basketball? & $\mathrm{f}$ & $\%$ \\
\hline 14 & 1 & 10.0 & 2 months & 1 & 10.0 \\
15 & 1 & 10.0 & 3 year & 2 & 20.0 \\
19 & 1 & 10.0 & 4 year & 2 & 20.0 \\
20 & 1 & 10.0 & 13 year & 1 & 10.0 \\
25 & 2 & 20.0 & 15 year & 1 & 10.0 \\
32 & 1 & 10.0 & 17 year & 2 & 20.0 \\
40 & 1 & 10.0 & 20 year & 1 & 10.0 \\
50 & 1 & 10.0 & Education & $\mathrm{f}$ & $\%$ \\
56 & 1 & 10.0 & Primary school & 3 & 30.0 \\
& & Middle school & 4 & 40.0 \\
& & High school & 3 & 30.0 \\
\hline
\end{tabular}

Table 2. Demographic characteristics of hearing impaired participants

\begin{tabular}{cccccc}
\hline Age & $\mathrm{f}$ & $\%$ & How long playing football? & $\mathrm{f}$ & $\%$ \\
\hline 17 & 1 & 10.0 & 1 year & 1 & 10.0 \\
20 & 1 & 10.0 & 3 year & 1 & 10.0 \\
23 & 2 & 20.0 & 5 year & 1 & 10.0 \\
25 & 1 & 10.0 & 10 year & 2 & 20.0 \\
30 & 2 & 20.0 & 13 year & 1 & 10.0 \\
34 & 1 & 10.0 & 15 year & 2 & 20.0 \\
39 & 1 & 10.0 & 19 year & 1 & 10.0 \\
45 & 1 & 10.0 & 21 year & 1 & 10.0 \\
& & & Education & $\mathrm{f}$ & $\%$ \\
& & & Primary school & 1 & 10.0 \\
& & Middle school & 1 & 10.0 \\
& & High school & 8 & 80.0 \\
\hline
\end{tabular}

\section{Results}

In this part, metaphors created by physically disabled and hearing impaired athletes concerning basketball/football and relevant branches are presented in tables.

Table 3. Metaphors about basketball/football branches

\begin{tabular}{cccccc}
\hline Basketball Metaphor & $\mathrm{f}$ & $\%$ & Football Metaphor & $\mathrm{f}$ & $\%$ \\
\hline family & 1 & 10.0 & tree & 1 & 10.0 \\
friend & 1 & 10.0 & chocolate & 1 & 10.0 \\
improve & 1 & 10.0 & life & 1 & 10.0 \\
life & 2 & 20.0 & peace & 1 & 10.0 \\
cling to life & 1 & 10.0 & hug & 1 & 10.0 \\
health & 1 & 10.0 & water & 3 & 30.0 \\
affection & 1 & 10.0 & sweet & 1 & 10.0 \\
sweet & 1 & 10.0 & family & 1 & 10.0 \\
indispensable & 1 & 10.0 & & & \\
\hline
\end{tabular}

Examining the Table 3, it is observed that, for the basketball branch, two physically disabled participants mentioned the life metaphor, while other metaphors were mentioned once. In addition, for the football branch, 
three hearing impaired participants mentioned the water metaphor, while other metaphors were stated once.

Table 4. Metaphors about basketball/football courts/fields

\begin{tabular}{cccccc}
\hline Basketball Court Metaphor & $\mathrm{f}$ & $\%$ & Football Field Metaphor & $\mathrm{f}$ & $\%$ \\
\hline family & 1 & 10.0 & duel & 1 & 10.0 \\
entertainment & 2 & 20.0 & home & 2 & 20.0 \\
energy & 2 & 20.0 & rainbow & 1 & 10.0 \\
home & 3 & 30.0 & showground & 1 & 10.0 \\
peace & 1 & 10.0 & peace & 1 & 10.0 \\
sadness & 1 & 10.0 & beach & 1 & 10.0 \\
& & & darling & 1 & 10.0 \\
& & & oasis & 1 & 10.0 \\
& & & nest & 1 & 10.0 \\
\hline
\end{tabular}

The metaphors created for the basketball/football courts/fields by the physically disabled and hearing-impaired athletes are presented in Table 4. Examining the table, concerning the basketball court, it is observed that three physically disabled participants mentioned the home metaphor, two of them used the entertainment, two participants mentioned energy, while other metaphors were used once. As per the football field, two hearing impaired athletes used the home metaphor, while other metaphors were used once.

Table 5. Metaphors about basketball/football ball

\begin{tabular}{cccccc}
\hline Basketball Ball Metaphor & $\mathrm{f}$ & $\%$ & Football Ball Metaphor & $\mathrm{f}$ & $\%$ \\
\hline world & 4 & 40.0 & hoop & 1 & 10.0 \\
diamond & 1 & 10.0 & energy & 1 & 10.0 \\
excitement & 2 & 20.0 & firework & 1 & 10.0 \\
happiness & 1 & 10.0 & hula hoop & 1 & 10.0 \\
dream & 1 & 10.0 & coffee & 1 & 10.0 \\
stress & 1 & 10.0 & organ & 3 & 30.0 \\
& & & wheel & 1 & 10.0 \\
& & & rosary & 1 & 10.0 \\
\hline
\end{tabular}

The metaphors created for the basketball/football (ball) by the physically disabled and hearing impaired athletes are presented in Table 5. Examining the table, concerning the basketball (ball), it was observed that four physically disabled participants mentioned the world metaphor, two stated the excitement metaphor, and other metaphors were mentioned once. As per the football (ball), three of the hearing impaired athletes used the organ metaphor, and other metaphors once.

Table 6. Metaphors about basketball/football match

\begin{tabular}{cccccc}
\hline Basketball Match Metaphor & $\mathrm{f}$ & $\%$ & Football Match Metaphor & $\mathrm{f}$ & $\%$ \\
\hline family & 2 & 20.0 & ferriswheel & 1 & 10.0 \\
enthusiasm & 1 & 10.0 & coffee & 1 & 10.0 \\
pride & 1 & 10.0 & gambling & 1 & 10.0 \\
excitement & 1 & 10.0 & struggle & 2 & 20.0 \\
shake off the nerves & 1 & 10.0 & freedom & 1 & 10.0 \\
peace & 1 & 10.0 & war & 2 & 20.0 \\
happiness & 1 & 10.0 & championship & 2 & 20.0 \\
health & 1 & 10.0 & & & \\
affection & 1 & 10.0 & & & \\
\hline
\end{tabular}

The metaphors created for playing basketball/football by the physically disabled and hearing impaired athletes are presented in Table 6. Examining the table, for playing basketball, it was observed that two physically disabled participants mentioned the family metaphor, and other metaphors were mentioned once. As per playing football, 
each of struggle, war, and championship metaphors was mentioned by two hearing impaired athletes, and other metaphors were mentioned once.

Table 7. Metaphors about basketball/football teammate

\begin{tabular}{cccccc}
\hline Basketball Teammate Metaphor & $\mathrm{f}$ & $\%$ & Football Teammate Metaphor & $\mathrm{f}$ & $\%$ \\
\hline elder brother & 1 & 10.0 & lion & 1 & 10.0 \\
family & 4 & 40.0 & tea time & 1 & 10.0 \\
friend & 2 & 20.0 & support & 1 & 10.0 \\
brother & 3 & 30.0 & world & 1 & 10.0 \\
& & & mouse & 1 & 10.0 \\
& & & tiger & 1 & 10.0 \\
& & cat & 1 & 10.0 \\
& & rowing & 1 & 10.0 \\
& & warrior & 1 & 10.0 \\
& & rabbit & 1 & 10.0 \\
\hline
\end{tabular}

The metaphors created for basketball/football teammates by the physically disabled and hearing impaired athletes are presented in Table 7. Examining the table, for basketball teammates, it was observed that four physically disabled participants mentioned the family metaphor, three of them mentioned the brother metaphor, two of them used the friend metaphor, and one participant used the elder brother metaphor. As per football teammates, hearing impaired athletes used each metaphor once.

Table 8. Metaphors about basketball/football coach

\begin{tabular}{cccccc}
\hline Basketball Coach Metaphor & $\mathrm{f}$ & $\%$ & Football Coach Metaphor & $\mathrm{f}$ & $\%$ \\
\hline family elder & 2 & 20.0 & chief & 1 & 10.0 \\
success & 4 & 40.0 & soldier & 1 & 10.0 \\
head of body & 1 & 10.0 & president & 1 & 10.0 \\
chocolate & 1 & 10.0 & Fatih Terim & 1 & 10.0 \\
captain & 1 & 10.0 & general & 1 & 10.0 \\
teacher & 1 & 10.0 & commander & 2 & 20.0 \\
& & & leader & 1 & 10.0 \\
& & & director & 1 & 10.0 \\
& & & manager & 1 & 10.0 \\
\hline
\end{tabular}

The metaphors created for basketball/football coaches by the physically disabled and hearing impaired athletes are presented in Table 8. Examining the table, for basketball coaches, it was observed that four physically disabled participants mentioned the success metaphor, two of them mentioned family elder metaphor, and other metaphors were mentioned once. As per football coaches, two hearing impaired athletes used commander metaphor, and other metaphors once.

Table 9. Metaphors about basketball/football spectator

\begin{tabular}{cccccc}
\hline Basketball Spectator Metaphor & $\mathrm{f}$ & $\%$ & Football Spectator Metaphor & $\mathrm{f}$ & $\%$ \\
\hline 6th person & 1 & 10.0 & cheerleader & 1 & 10.0 \\
family meeting & 1 & 10.0 & parents & 1 & 10.0 \\
enthusiasm & 2 & 20.0 & enthusiasm & 1 & 10.0 \\
support & 2 & 20.0 & fizzy drink & 1 & 10.0 \\
power & 1 & 10.0 & power & 2 & 20.0 \\
excitement & 1 & 10.0 & driving force & 1 & 10.0 \\
happiness & 2 & 20.0 & ant & 1 & 10.0 \\
& & & military & 1 & 10.0 \\
& & & spider web & 1 & 10.0 \\
\hline
\end{tabular}


The metaphors created for basketball/football spectators by the physically disabled and hearing impaired athletes are presented in Table 9. Examining the table, for basketball spectators, it was observed that each of the enthusiasm, support, and happiness metaphors were mentioned by two physically disabled participants, and other metaphors were mentioned once. As per football spectators, two hearing impaired athletes used strength metaphor, and other metaphors were mentioned once.

Table 10. Metaphors about being physically disabled by the hearing impaired and physically disabled athletes

\begin{tabular}{cccccc}
\hline $\begin{array}{c}\text { (Physically Disabled Athletes) } \\
\text { Physical Disability Metaphor }\end{array}$ & $\mathrm{f}$ & $\%$ & $\begin{array}{c}\text { (Hearing Impaired Athletes) } \\
\text { Physical Disability Metaphor }\end{array}$ & $\mathrm{f}$ & $\%$ \\
\hline advantage & 1 & 10.0 & colorful candy & 1 & 10.0 \\
privilege & 3 & 30.0 & child & 1 & 10.0 \\
world & 1 & 10.0 & diversity & 1 & 10.0 \\
fate & 1 & 10.0 & klaxon & 1 & 10.0 \\
brotherhood & 1 & 10.0 & neediness & 1 & 10.0 \\
tax & 1 & 10.0 & wheelless car & 1 & 10.0 \\
walk & 1 & 10.0 & half of an apple & 1 & 10.0 \\
difficulty & 1 & 10.0 & incomplete person & 1 & 10.0 \\
& & & kitten & 1 & 10.0 \\
& & & weakness & 1 & 10.0 \\
\hline
\end{tabular}

The metaphors created for being physically disabled by the hearing impaired and physically disabled athletes are presented in Table 10. Examining the table, for being physically disabled, it was observed that three physically disabled participants mentioned the privilege metaphors, and other metaphors were mentioned once. As per hearing impaired athletes, they used each metaphor once.

Table 11. Metaphors about being hearing impaired by the hearing impaired and physically disabled athletes

\begin{tabular}{cccccc}
\hline $\begin{array}{c}\text { (Physically Disabled Athletes) } \\
\text { Hearing Impairment Metaphor }\end{array}$ & $\mathrm{f}$ & $\%$ & $\begin{array}{c}\text { (Hearing Impaired Athletes) } \\
\text { Hearing Impairment Metaphor }\end{array}$ & $\mathrm{f}$ & $\%$ \\
\hline different world & 2 & 20.0 & baby & 1 & 10.0 \\
flower & 1 & 10.0 & wall & 1 & 10.0 \\
friend & 1 & 10.0 & difficulty & 1 & 10.0 \\
pigeon & 1 & 10.0 & light & 1 & 10.0 \\
blankness & 1 & 10.0 & silence & 5 & 50.0 \\
silent world & 1 & 10.0 & reticence & 1 & 10.0 \\
difficult & 2 & 20.0 & & & \\
square the circle & 1 & 10.0 & & & \\
\hline
\end{tabular}

The metaphors created for having hearing impairment by the physically disabled and hearing impaired athletes are presented in Table 11. Examining the table, for having hearing impairment, it was observed that each of $a$ different world and difficult metaphors were mentioned by two physically disabled participants, and other metaphors were mentioned once. As per having hearing impairment, five of hearing impaired athletes used the silence metaphor, and other metaphors were mentioned once.

Table 12. Metaphors about being disabled by the hearing impaired and physically disabled athletes

\begin{tabular}{cccccc}
\hline $\begin{array}{c}\text { (Physically Disabled Athletes) } \\
\text { Disability Metaphor }\end{array}$ & $\mathrm{f}$ & $\%$ & $\begin{array}{c}\text { (Hearing Impaired Athletes) } \\
\text { Disability Metaphor }\end{array}$ & $\mathrm{f}$ & $\%$ \\
\hline support & 1 & 10.0 & aquarium & 1 & 10.0 \\
exclusion & 1 & 10.0 & smokeless house & 1 & 10.0 \\
disability & 1 & 10.0 & candy apple & 1 & 10.0 \\
awareness & 1 & 10.0 & disease & 2 & 20.0 \\
siblings & 1 & 10.0 & neediness & 1 & 10.0 \\
national lottery & 1 & 10.0 & rehabilitation center & 1 & 10.0 \\
\hline
\end{tabular}




\begin{tabular}{cccccc}
\hline struggle & 1 & 10.0 & saltless meal & 1 & 10.0 \\
health & 1 & 10.0 & Turkish coffee & 1 & 10.0 \\
society & 1 & 10.0 & incomplete person & 1 & 10.0 \\
difficulty & 1 & 10.0 & & & \\
\hline
\end{tabular}

The metaphors created for being disabled by the physically disabled and hearing impaired athletes are presented in Table 12. Examining the table, for being disabled, it was observed that physically disabled participants mentioned each metaphor once. As per for being disabled, two of the hearing impaired athletes used the disease metaphor, and other metaphors were used once.

\section{Discussion and Conclusion}

Sports enables people with disabilities to express themselves and integrate into society. Ensuring that sports plays a part at every step of life of disabled individuals is one of the social responsibilities. Therefore, it is important to determine how the disabled individuals perceive sports and achievements to date for recognizing this responsibility. The results of this study are considered to be important in understanding how the perceptions of disabled individuals concerning their sports branches are formed and in determining the importance of sports on disabled individuals.

One of the results of the study is comprised of the metaphors of physically disabled and hearing impaired athletes concerning the basketball and football branches. In these metaphors, two physically disabled athletes used the life metaphor for the basketball branch, and the other metaphors were used once. Additionally, three hearing impaired athletes used the water metaphor for the football branch, the other metaphors were used once, and it was observed that the athletes used positive metaphors for their branches. In this context, it was determined that the sports branches of physically disabled and hearing impaired athletes were the focal points of their lives, and the athletes mentioned about them as the requirements for their lives. We can state that the reason is the fact that the athletes experience the positive effects of sports in their developmental areas. In previous studies, it was also stated that the metaphors of disabled individuals concerning sports were positive, and sports had positive effects on their lives (Güler et al., 2019; Farrell et al., 2004; Kristen et al., 2002; Fitzgerald et al., 2003).

Another result of the study is comprised of metaphors of disabled athletes about the basketball court and football field. In these metaphors, three participants used the home metaphor for the basketball court, two used entertainment and energy metaphors, while other metaphors were used once. For the football field, two participants used the home metaphor, while other metaphors were used once. Physically disabled and hearing impaired athletes used positive metaphors for the basketball court and football field. In this respect, we can say that physically disabled and hearing impaired athletes perceive the basketball courts and football fields as places where they feel comfortable and safe. In addition, the description of the basketball court by physically disabled athletes with entertainment and energy metaphors can be interpreted in a way that these individuals are happy to be on the court/field and they feel dynamic. In previous studies, it was determined that the presence of disabled individuals in sports environments positively affects and stimulates them (Watson \& Parker, 2012; Anderson, 2009).

Another result of the study is comprised of the metaphors created for basketball and football (ball) by the disabled athletes. In these metaphors, four participants used the world for the basketball (ball), two people used the excitement metaphor, while other metaphors were used once. For the football (ball), three participants used the organ metaphor, while each other metaphor was used once. It was observed that physically disabled and hearing-impaired athletes used a positive metaphor for the ball. Accordingly, we can say that the ball is important in the lives of the physically disabled and hearing impaired athletes, and they see it as a part of their body. Similarly, in a previous study conducted by Yetim et al. (2018), it was determined that badminton athletes perceived the racquet as an organ of their body.

Another result of the study is comprised of the metaphors created for playing basketball and football by the disabled athletes. In these metaphors, for playing basketball, two participants used family metaphor, while other metaphors were used once. Concerning playing football, each metaphor of struggle, war, and championship were used for two times, while other metaphors were used once. In this respect, we can say that athletes with physical disabilities perceive the game environment as a warmer and a more sincere atmosphere. However, we can say that hearing impaired athletes perceive the football environment as a more competitive atmosphere with a focus on winning. Similarly, it was reported in previous studies conducted on disabled individuals that the concept of sports is associated with metaphors of military language such as war and struggle (Smith \& Sparkes, 2004). Kleiber and Hutchinson (1999) argue that sports and military metaphors evoke masculine ideals and a sense of heroic struggle that can be restrictive for individuals with physical disabilities (Kleiber \& Hutchinson, 1999). 
Another result of the study is comprised of the metaphors created for teammates by the disabled athletes. In these metaphors, for a basketball teammate, four participants used the family metaphor, three participants used the brother metaphor, two of them used friend and one participant used the elder brother metaphor. For the football teammates, the metaphors of lion, tea time, support, world, mouse, tiger, cat, rowing, warrior, and rabbit metaphors were used each once. In this respect, we can say that disabled athletes playing basketball perceive their teammates as their closest friends. We can say that hearing impaired individuals playing football define their teammates rather with power, strength, and association. Similarly, O'Keefe (2005) stated that disabled athletes defined their teammates with power, strength, and support by using often animal metaphors.

Another result of the study is comprised of metaphors created for basketball and football coaches by the disabled athletes. In these metaphors, for the basketball coach, four participants used the success metaphor, two participants used the family elder, while the other metaphors were used once. Concerning the football coach, two participants used the commander metaphor, while other metaphors were used once. In this respect, we can say that disabled athletes playing football perceive the coach rather like a leader. Similarly, previous studies emphasized that the coach is important for disabled individuals and it is effective for individuals to participate in sports (Jason et al., 2015).

Another result of the research is comprised of the metaphors created for the spectator of basketball and football by the disabled athletes. In these metaphors, each of the enthusiasm, support, and happiness metaphors were used by two participants for the basketball supporters, while other metaphors were used once. Two participants used strength metaphor for the football supporters, while other metaphors were used once. In this respect, we can say that physically disabled and hearing impaired athletes perceive the supporters as strength and support, and see this as a source of motivation. In another study conducted by Cottingham et al. (2012) it was similarly emphasized that spectators or fans are one of the most important features of the sports environment in the disabled sports.

Another result of the study is comprised of the metaphors created by the disabled athletes for being physically disabled and having hearing impairments. In these metaphors, for being physically disabled, three of the physically disabled athletes used the privilege metaphors, while other metaphors were used once. As per the hearing impaired athletes, they used the metaphors of colorful candy, child, diversity, klaxon, neediness, wheelless car, half an apple, incomplete person, kitten, and weakness for physical disability. In this respect, we can say that the metaphors that physically disabled and hearing impaired individuals use about their disabilities are more negative. In metaphors for hearing impairment, two physically disabled athletes used a different world and difficult metaphors, while other metaphors were used once. For having hearing impairment, five hearing impaired athletes used the silence metaphor, while other metaphors were used once. We can say that athletes in both groups of disabilities have negative perceptions of both having hearing impairment and physical disability. In previous studies, it was reported that disabled individuals create negative metaphors for themselves and they explain the negative effects of disability for themselves in negative metaphors (Pennebaker, Hughes, \& O'Heeron, 1987; Whaley \& Parker, 2000).

Another result of the study is comprised of the metaphors created by physically disabled and hearing impaired athletes for being disabled. In these metaphors, physically disabled athletes used metaphors of support, exclusion, disability, awareness, siblings, national lottery, struggle, health, society, and difficulty. As per the hearing impaired athletes, two of them used the disease metaphor, while other metaphors were used once. In this respect, it was determined that the perceptions of disabled athletes regarding the concept of disability were generally negative. The disability metaphors used in the previous studies support our research (Peter, 2011; Thomas, 2012; Smith \& Sparkes, 2008; Lindemann, 2008).

Consequently, it can be mentioned that physically disabled and hearing impaired athletes place sports in an important place in their lives and realize themselves, socialize, and feel free through sports. However, although the perceptions of disability are generally negative, we can say that sports have changed these perceptions in a positive way and they perceive sports as a source of life. In addition to the social, physical, and psychological benefits of sports to healthy individuals, it also has the same effects on individuals with disabilities; in this regard, the importance of physical education and sport in disabled people is once again emerging. Therefore, it is considered that the results of this study are significant since it suggests encouraging disabled individuals for doing sports, helping them participate in sports, providing support, and promoting the disabled sports.

\section{Limitations and Suggestions}

This study was conducted solely on disabled athletes playing at physically disabled basketball and hearing impaired football teams in Muş province. For future studies, it is suggested to include different provinces in order to increase the sample size and allow the results to diversify. In addition, this study was conducted with 20 disabled 
athletes playing in physically disabled basketball and hearing impaired football teams. For further studies, it is suggested to include higher number of teams in order to allow for the opportunity to make comparisons with different branches.

\section{References}

Aslan, S. (2019). Perceived Stress Level and Sports Participation in Deaf Adolescents and Young Adults. Journal of Education and Training Studies, 7(3), 197-201. https://doi.org/10.11114/jets.v7i3.3974

Aslan, S.., Aslan, U. B., \& Uyan, A. (2017). Comparison of self-esteem in physically disabled people according to participating sports. Journal of Human Sciences, 14(4), 4032-4040. https://doi.org/10.14687/jhs.v14i4.4471

Bantjes, J., Swartz, L., Conchar, L., \& Derman, W. (2015). Developing Programmes to Promote Participation in Sport among Adolescents with Disabilities: Perceptions Expressed by a Group of South African Adolescents with Cerebral Palsy. International Journal of Disability, Development and Education, 62(3), 288-302. https://doi.org/10.1080/1034912X.2015.1020924

Bilir, S. (1986). Children with Disabilities and Their Education. Hacettepe University, Department of Child Development and Education, Ankara: Ayyildiz Printing House.

Brittain, I. (2004). The role of schools in constructing self-perceptions of sport and physical education in relation to people with disabilities. Sport, Education and Society, 9, 75-94. https://doi.org/10.1080/1357332042000175827

Comensoli, P.A. (2011). Descending the Ladder: The Theological Anthropology of Jean Vanier's Key Metaphor. Journal of Religion, Disability \& Health, 15(2), 115-129. https://doi.org/10.1080/15228967.2011.565572

Cottingham, M., Chatfield, S., Gearity, B. T., Allen, J. T., \& Hall, S. A. (2012). Using points of attachment to examine repatronage and online consumption of wheelchair rugby spectators. International Journal of Sport Management, 13(2), 160-172.

Farrell, R. J., Crocker, P. R. E., McDonough, M. H., \& Sedgwick, W. A. (2004). The driving force: Motivation in Special Olympics. Adapted Physical Activity Quarterly 21(2), 153-166. https://doi.org/10.1123/apaq.21.2.153

Fitzgerald, H., Joblıng, A., \& Kirk, D. (2003) Physical Education and pupil voice: listening to the 'voices' of students with severe learning difficulties through a task-based approach to research and learning in physical education. Support for Learning, 18(3), 123-129. https://doi.org/10.1111/1467-9604.00294

Goodwin, D. L., Thurmeier, R., \& Gustafson, P. (2004). Reactions to the metaphors of disability: The mediating effects of physical activity. Adapted Physical Activity Quarterly, 21, 379-398. https://doi.org/10.1123/apaq.21.4.379

Jaarsma, E. A., Dijkstra, P. U., de Blécourt, A. C., Geertzen, J. H., \& Dekker, R. (2015). Barriers and facilitators of sports in children with physical disabilities: a mixed-method study. Disability and Rehabilitation, 37(18), 1617-1625. https://doi.org/10.3109/09638288.2014.972587

Kemper, H. G. C., Ooijendijk, W. T. M., \& Stiggelbout, M. (2000). Consensus on the Dutch standard of healthy exercise. Tijdschrift voor Gezondheidswetenschappen/TSG, 78, 180-183.

Kissow, A. M. (2015). Participation in physical activity and the everyday life of people with physical disabilities: a review of the literature. Scandinavian Journal of Disability Research, 17(2), 144-166. https://doi.org/10.1080/15017419.2013.787369

Kleiber, D. \& Hutchinson, S. (1999). Heroic masculinity in the recovery from spinal cord injury. In A. Sparkes, \& M. Silvennoinen (Eds.), Talking bodies: Men's narratives of the body and sport (Jyvaskyls, Finland, University of Jyvaskyla, SoPhi).

Krısten, L., Partıksson, G., \& Fridlund, B. (2002). Conceptions of children and adolescents with physical disabilities about their participation in a sports programme. European Physical Education Review, 8(2), 139-156. https://doi.org/10.1177/1356336X020082003

Lastuka, A., \& Cottingham, M. (2016). The effect of adaptive sports on employment among people with disabilities. Disability and Rehabilitation, 38(8), 742-748. https://doi.org/10.3109/09638288.2015.1059497

Lindemann, K. (2008). I Can't Be Standing Up Out There: Communicative Performances of (Dis)Ability in Wheelchair Rugby. Text and Performance Quarterly, 28(1-2), 98-115. 
https://doi.org/10.1080/10462930701754366

Lorenzo, T., McKinney, V., Bam, A., Sigenu, V., \& Sompeta, S. (2019). Mapping participation of disabled youth in sport and other free-time activities to facilitate their livelihoods development. British Journal of Occupational Therapy, 82(2), 80-89. https://doi.org/10.1177/0308022618817281

Morgan, G. (1980). Paradigms, metaphors, and puzzle solving in organizational analysis. Administrative Science Quarterly, 25, 606-622. https://doi.org/10.2307/2392283

Nemček, D. (2016). Quality of life of people with disabilities from sport participation point of view. Acta Facultatis Educationis Physicae Universitatis Comenianae, 56(2), 77-92. https://doi.org/10.1515/afepuc-2016-0007

Pennebaker, J. W., Hughes, C. F., \& O'Heeron, R. C. (1987). The psychophysiology of confession: Linking inhibitory and psychosomatic processes. Journal of Personality and Social Psychology, 52, 781-793. https://doi.org/10.1037/0022-3514.52.4.781

Şahan, B. S., Veysel, T., \& Kazım, N. (2016). Determination of the individuals' hopelessness levels participating in sportive recreation activities in terms of some variables, Inonu University. Journal of Physical Education and Sport Sciences, 3(1), 66-82.

Sherrill, C. (1998). Adapted physical activity, recreation and sport: Crossdisciplinary and lifespan. WCB/McGraw Hill, 2460 Kerper Blvd., Dubuque, IA 52001.

Siedentop, D. (1998). What is sport education and how does it work? Journal of Physical Education, Recreation \& Dance, 69(4), 18-20. https://doi.org/10.1080/07303084.1998.10605528

Smith, B., \& Sparkes, A. (2004) Men, sport, and spinal cord injury: An analysis of metaphors and narrative types. Disability \& Society, 19(6), 613-626. https://doi.org/10.1080/0968759042000252533

Smith, B., \& Sparkes, A.C. (2008). Changing bodies, changing narratives and the consequences of tellability: A case study of becoming disabled through sport. Sociology of Health \& Illness, 30(2), 217-236. https://doi.org/10.1111/j.1467-9566.2007.01033.x

Stewart, D. A. (1991). Deaf sport: The impact of sports within the deaf community. Washington, DC: Gallaudet University Press.

Stewart, D. A., \& Ellis, M. K. (2005). Sports and the deaf child. American Annals of the Deaf, 150(1), 59-66. https://doi.org/10.1353/aad.2005.0023

Thomas, C. (2002). The 'disabled' body. In M. Evans, \& E. Lee (Eds.), Real Bodies. Basingstoke: Palgrave. https://doi.org/10.1007/978-0-230-62974-5_5

Watson, N., \& Parker, A. (2012). Christianity, Sport and Disability: A Case Study of the Role of Long-Distance Running in the Life of a Father and his Son who is Congenitally Blind and has Profound Intellectual Disabilities. Practical Theology, 5(2), 189-207. https://doi.org/10.1558/prth.v5i2.189

Whaley, B. B., \& Parker, R. G. (2000). Expressing the experience of communicative disability: Metaphors of persons who stutter. Communication Reports, 13(2), 115-125. https://doi.org/10.1080/08934210009367729

WHO. (2017). Disabilities. World Health Organization. Retrieved from http://www.who.int/topics/disabilities/en/

Winnick, J., \& Porretta, D. L. (2016). Adapted physical education and sport. Human Kinetics.

Yetim, G., Bidil, S., \& Argan, M. (2018). The meeting point of feather and ball: A metaphor research. International Journal of Social Sciences and Education Research, 4(3), 530-546. https://doi.org/10.24289/ijsser.435229

Yıldırım, A., \& Şimşek, H. (2011). Qualitative research methods in the social sciences (8th ed.). Ankara: Seckin Publishing House.

\section{Copyrights}

Copyright for this article is retained by the author(s), with first publication rights granted to the journal.

This is an open-access article distributed under the terms and conditions of the Creative Commons Attribution license (http://creativecommons.org/licenses/by/4.0/). 